\title{
Evidence-based ethics
}

Shaun Sellars continues this exciting and essential series on ethical dilemmas in dentistry which appears in every second issue of the $B D J$

We're all aware of the Hippocratic oath, the concept of 'first do no harm, but in our day to day work, we routinely remove teeth and carry out other surgeries which could, in isolation, be considered harmful. Perhaps a better rule to live by would be to 'provide the greatest benefit to patients. But how do we know that the treatments and preventative measures we apply are beneficial to patients, and aren't causing them issues in the long term?

You can only have a truly beneficent profession, if you have an evidence-based profession. If you have a variety of treatment options available to present to your patient, and you're trying to do the best you can for a patient, then unless you know which treatment is likely to produce the best result for that particular patient, by whichever measure of 'best' you choose to use, then you will always have a degree of uncertainty.

If, however, you have high quality research to back up these options, you can pass that information on to the patient. Being able to say 'I know that my team has a $95 \%$ success rate with this treatment at ten years' would be immensely beneficial to both practitioner and patient.

Evidence-based dentistry can still be considered to be in its infancy, with significant evidence gaps both in amount and quality of evidence available on which to make judgements. There is also a degree of scepticism towards evidence-based dentistry, and a viewpoint of 'I know what works best in my hands' from a degree of the profession. This disregards both the fact that our views are affected by a myriad of cognitive biases, and that true evidence-based dentistry takes personal experience into account. Unsurprisingly, this response mirrors that from doctors when evidence-based medicine was first conceptualised in the early 1970s.

To help with this we should be encouraging open access publishing of research as well as increasing the amount of research done in practice, which we should all consider contributing to. There's a huge opportunity for primary care research to be undertaken

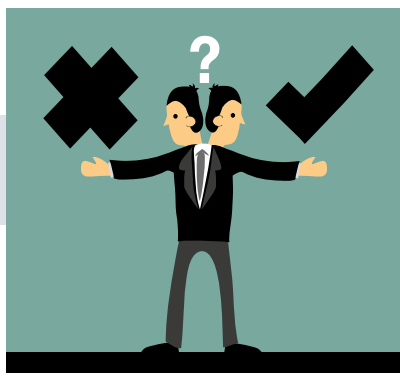

which could give us real-world data that is likely to be of real use in everyday dentistry.

Efforts should be made to increase the quality of research produced, as large amounts of the available research is of poor quality or outdated. Finally, we should constantly be on the lookout for ways to improve our practice, taking the whole of the evidence base into consideration. By taking a Bayesianstyle approach to adaptation of techniques and procedures, our best practice treatments would take into consideration the full extent of the evidence base, appropriately weighted in relation to the quality of evidence available, rather than the current approach of different camps playing research paper ping-pong to justify their treatment methods.

Evidence-based dentistry is ethical dentistry. If we move to a more evidence-based profession, we move to a more ethical profession, to the benefit of our patients, and to ourselves.

\section{Malala Yousafzai makes inspirational address in Birmingham}

Nobel Prize winner Malala Yousafzai opened this year's British Association of Oral and Maxillofacial Surgeons (BAOMS) conference in Birmingham with an address aimed at inspiring women maxillofacial surgeons.

In 2012, Malala Yousafzai was shot in the head by a Taliban gunman in an assassination attempt because of her activism, writing a blog under a pseudonym describing her life during the Taliban occupation of Swat, Pakistan. Malala was brought to the Queen Elizabeth Hospital in Birmingham for treatment under the care of Maxillofacial Consultant and BAOMS President Sat Parmar.

In a question and answer session with Sat Parmar and Consultant Maxillofacial Surgeon Daljit Dhariwal, Malala explained 'a life without an education I would never be able to fulfil myself - only known as someone's sister or wife. That's why I decided to speak out. I could have stayed silent but it would have had worse consequences'.

She said that her school uniform became a symbol of her resilience and also for all those young women who have a right to an education.

Sat Parmar asked her why women don't progress in surgery when ' $60 \%$ of admissions to medical school are women...do you have any advice?'

Malala Yousafzai said: 'It is an issue globally. It is surprising that women do lack that representation. This is a global topic that we need to talk about.'

Malala called on women and girls to be themselves: 'It's about inspiring the younger generations. There are invisible challenges

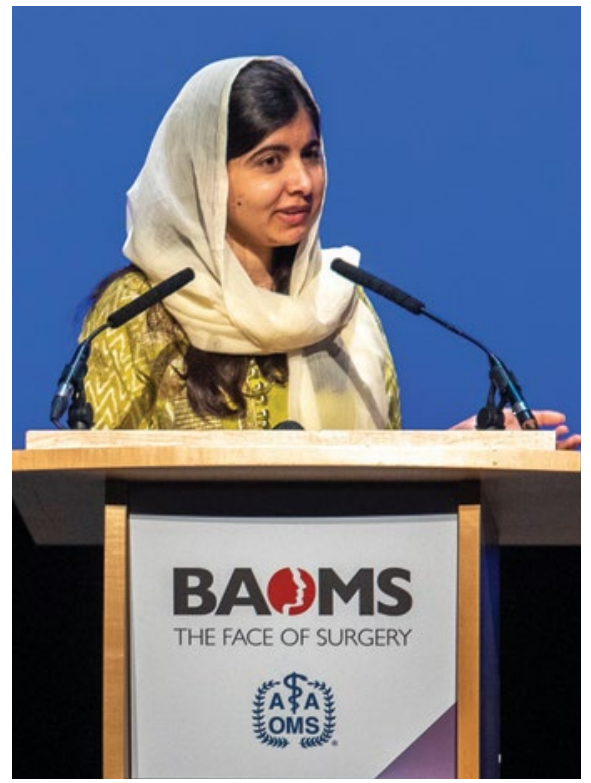

Malala Yousafzai

out there, and we need to break that glass ceiling and fight that inner feeling that it's not for them.' 